\title{
New oral health groups for children and the elderly in $\mathrm{NI}$
}

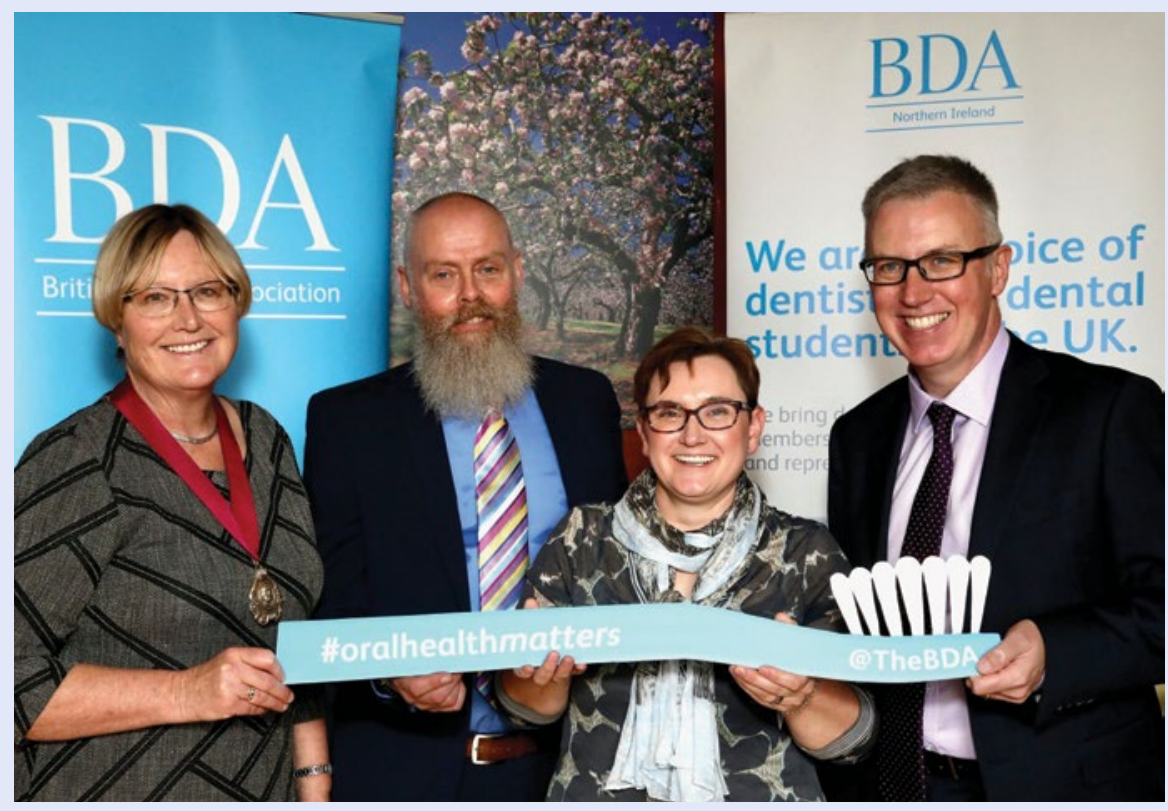

From left to right: Roz McMullan, President, BDA; Simon Reid, Chief Dental Officer for Northern Ireland; Caroline Lappin, Chair of the BDA's NI Council; Michael Donaldson, Head of Dental Services, Health \& Social Care Board (HSCB)

The British Dental Association (BDA) has welcomed an announcement by the Department of Health to establish two new groups focusing on the oral health of children and the elderly in Northern Ireland. However, any action will need to be accompanied by adequate investment and a commitment to address the needs of the dental workforce if it is to be successful, the BDA warned.

Chief Dental Officer Simon Reid made the announcement at the BDA Oral Health Matters event at Stormont on 17 October, a landmark oral health event calling for a new vision for oral health in Northern Ireland. The event featured a capacity crowd of key stakeholders including Health Spokespersons of the main political parties, the Older Person's Commissioner, policymakers, advocates, leading public health organisations and charities.

BDA Northern Ireland has campaigned over many years for action to deliver improved oral health outcomes in Northern Ireland, in particular for children and the elderly. The current Oral Health Strategy is now 12 -years-old, having been launched in 2007.

According to the latest Child Dental Health Survey published in 2015, just $19 \%$ of 15 -year-olds in Northern Ireland were considered to have 'good oral health'. In 2017/18, 4,724 children faced tooth extraction under general anaesthetic in Northern Ireland (3 times pro-rata than England).

BDA Northern Ireland has also highlighted the mounting pressures on dentists to meet the increased challenges from a growing ageing population that is increasingly retaining some natural teeth into old age.

\section{Can you do more to help keep antibiotics working?}

National dental organisations supported

World Antibiotic Awareness Week (18-22

November) by reminding the dental

profession about the importance of using antibiotics judiciously.

The Faculty of General Dental Practice UK, the Association of Clinical Oral Microbiologists, the Association of Dental Hospitals, the British Association of Oral Surgeons and the dental sub-group of the Scottish Antimicrobial Prescribing Group have all welcomed the steady reduction in the number of antibiotic prescriptions issued in NHS primary dental care since 2011 including a $9 \%$ reduction over the last year 尊- but say more can be done to further reduce inappropriate prescribing in dentistry.

Antibiotic-resistant infections are 兽 expected to increase markedly over the 善 next 20 years due to over-prescribing, $\circlearrowleft$ leading to even simple surgical procedures becoming high-risk due to the potential for post-surgical infection with resistant micro-organisms.

With an estimated one in six patients prescribed antibiotics each year as part of their NHS dental treatment, dentistry accounts for around $5-7 \%$ of NHS antibiotic prescriptions, including $60 \%$ of metronidazole prescriptions in primary care. The organisations say the profession can do more to help keep antibiotics working by ensuring that every prescription is justified according to clinical need and national guidelines.

Dentists are also encouraged to update their knowledge by participating in a national survey of antibiotic prescribing (https://bit. ly/2rfhkbu), and taking the antimicrobial stewardship (AMS) e-learning modules (https://www.baos.org.uk/elearning/), both of which provide free verifiable CPD.

A free dental AMS toolkit endorsed by the organisations provides patient information highlighting that antibiotics do not cure toothache, advice for dentists on the use of analgesics, and an antimicrobial prescribing self-audit tool: https://www. gov.uk/guidance/dentalantimicrobialstewardshiptoolkit.

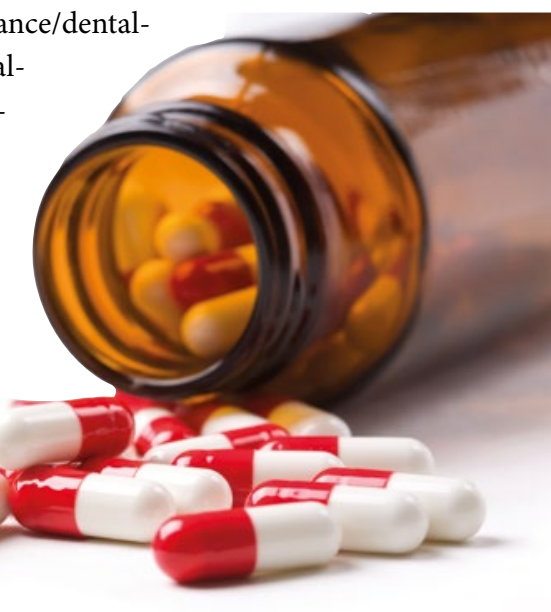

